Chapter 9

\title{
Application of Mixed Microbial Culture Biofilms for Manganese (II), Cobalt (II), and Chromium (VI) Biosorption by Horizontal Rotating Tubular Bioreactor
}

\author{
Tonči Rezić, Iva Rezić, Michaela Zeiner and \\ Božidar Šantek
}

Additional information is available at the end of the chapter

http://dx.doi.org/10.5772/66920

\begin{abstract}
Industrial wastewater contaminated with toxic heavy metals is a big ecological and environmental problem. Applying biological materials to effectively remove and recover heavy metals from contaminated wastewaters has gained importance as promising alternative to conventional treatment techniques. Thus, the objective of the presented paper is the investigation of the capability of microorganisms, isolated from polluted (metal-laden) soil, to biosorb toxic metals from aqueous solutions. Biosorption process for heavy metal removal was conducted in a new pilot scale horizontal rotating tubular bioreactor (HRTB). This bioreactor provides conditions for microorganism's growth in a form of suspended cells and biofilm. Biofilm is capable to protect microorganisms from interaction with toxic metals in the surrounding environment. Three metals were selected as model examples: cations of manganese and cobalt and hexavalent chromium (an oxyanion). Optimized bioreactor conditions, namely, medium inflow rate $(F)$ and bioreactor rotation speed $(n)$ for biofilm formation and metal removal were monitored, and under optimized bioreactor conditions, promising results were obtained.
\end{abstract}

Keywords: heavy metals, mixed microbial culture, biosorption, biofilm, horizontal rotating tubular bioreactor

\section{Introduction}

Heavy metal's wastewater pollution has always been a very serious problem because these elements are not biodegradable and can accumulate in living tissues causing serious health effects [1]. Heavy metals are introduced into the natural environment through many industrial 
processes including leather tanning, wood preservation, metal plating, mining operations, chloralkali, radiator manufacturing, smelting, alloy industries, storage batteries, and automobile manufacturing [2]. Since the early 1970s, there has been growing concern over the effect of heavy metals on humans and aquatic ecosystems [3]. The Agency for Toxic Substances and Disease Registry (ATSDR) classifies nickel as a human carcinogen based on its chronic and subchronic effects [4]. Iron and copper can cause stomach and intestinal distress, liver and kidney damage, and anemia. Zinc may cause anemia, damage the pancreas, and decrease levels of high-density lipoprotein (HDL) cholesterol [5].

There are many conventional methods (physical and chemical) for heavy metal removal, but in general, they result with much waste which is hard to treat. In addition, several widely applied processes such as ion exchange, membrane technologies, and adsorption are very expensive processes when used for large quantities of wastewater which contain low concentrations of heavy metals [6]. Heavy metals may be removed from water as an insoluble soil by the chemical process of precipitation, respectively. However, chemical treatment of heavy metals generates environmentally hazardous chemical byproducts. Additionally, chemical treatment requires constant adjustment of $\mathrm{pH}$ value to a narrow range for optimal heavy metal removal, thereby increasing the labor input and cost [7].

As an alternative, different biochemical methods can be applied because they do not destroy metals, but concentrate and immobilize them [8]. Biosorption is removal of metals and their complexes from samples by biological materials [9]. Bioadsorbens can efficiently remove heavy metals from solutions with low concentration; therefore, they are ideal adsorptive media for wastewaters with low concentrations of metal ions. Microbial metal accumulation has received much attention during recent years, due to the potential use of microorganisms for treatment of metal-polluted water or wastewater streams. Recently, several bacterial species have been identified to remove toxic heavy metals [10, 11]. Biosorption can be performed on live or dead microorganisms, as well as on their parts or extracellular products and microorganism aggregations on the surfaces in the structures called biofilm. Biofilm application in the biosorption showed great potential in the wastewater treatment systems. Different types of bioreactor systems such as trickling filters, fluidized or packed bed bioreactors, and thin layer or biodisc reactors were implemented for biofilm formation and wastewater treatment [12-14]. Horizontal rotating tubular bioreactor (HRTB) was designed as combination of a thin layer $[15,16]$ and biodisc reactor [17] with construction abilities for successful biofilm formation. Consequently, bioreactor interior is equipped with o-shaped partitional walls which provide area for biofilm formation. Wide investigation of HRTB mixing properties was previously done [18-22], and aerobic and anaerobic bioprocesses were successfully conducted. As a model of anaerobic bioprocess, fermentative glucose conversion was chosen [23]. Acetate removal with mixed microbial culture was selected as a model bioprocess for study of HRTB performance in aerobic condition [24]. As combination of aerobic and anaerobic bioprocesses, nitrification and denitrification were done in two consecutive steps in the same bioreactor vessel [25].

In this investigation HRTB was used for native mixed microbial biofilm formation and investigation of developed biofilm biosorption abilities. In the biosorption experiments, artificial wastewater with heavy metal ions $\mathrm{Co}(\mathrm{II}), \mathrm{Cr}(\mathrm{VI})$, and $\mathrm{Mn}$ (II) was applied as representative example of 
textile industry wastewaters. Observed results showed significant potential of developed mixed microbial culture biofilm to successfully remove toxic heavy metals in applied bioreactor.

\section{Material and methods}

\subsection{Microorganism, medium, and growth conditions}

Mixed microbial culture was isolated from surface sediments sampled in the Kaštela bayindustrial area located near town Split, at the Croatia Adriatic coast. Isolation was done from $5 \mathrm{~g}$ of soil samples. Samples were resuspended in Erlenmeyer flasks with different contents of heavy metals in feeding medium (Table 1 ) and cultivated $48 \mathrm{~h}$ at $23 \pm 1^{\circ} \mathrm{C}$. Rotation speed during cultivation was $150 \mathrm{rpm}$. After $48 \mathrm{~h}$ flat plates were inoculated with $1 \mathrm{~mL}$ sample from each flask. Medium content used for flat plate cultivation was the same as shown in Table 1 with $20 \mathrm{~g} / \mathrm{L}$ of agar. Viable cells were determined as colony-forming units (CFU 1/mL). The number of colonies was counted after $48 \mathrm{~h}$ at $23 \pm 1^{\circ} \mathrm{C}$. Only medium 1 provided satisfied condition for microorganism colony forming. Therefore, this medium was used for cultivation in tank bioreactor and HRTB. In this research, the medium was sterilized at $121^{\circ} \mathrm{C}$ for $20 \mathrm{~min}$.

\begin{tabular}{|c|c|c|c|c|}
\hline Content $\left(\mathrm{g} \mathrm{L}^{-1}\right)$ & Medium 1 & Medium 2 & Medium 3 & Medium 4 \\
\hline Glucose & 10.00 & 10.00 & 10.00 & 10.00 \\
\hline Yeast extract & 3.00 & 3.00 & 3.00 & 3.00 \\
\hline Tripton & 3.00 & 3.00 & 3.00 & 3.00 \\
\hline $\mathrm{CuSO}_{4} \cdot 5 \mathrm{H}_{2} \mathrm{O}$ & - & 0.49 & 0.49 & 0.49 \\
\hline $\mathrm{ZnSO}_{4} \cdot 7 \mathrm{H}_{2} \mathrm{O}$ & - & 0.55 & - & 0.55 \\
\hline $\mathrm{CoCl}_{2} \cdot 6 \mathrm{H}_{2} \mathrm{O}$ & 0.51 & 0.50 & 0.50 & 0.50 \\
\hline $\mathrm{FeSO}_{4} \cdot 7 \mathrm{H}_{2} \mathrm{O}$ & - & 0.62 & 0.62 & 0.62 \\
\hline $\mathrm{MnSO}_{4} \cdot \mathrm{H}_{2} \mathrm{O}$ & 0.39 & - & 0.39 & 0.39 \\
\hline $\mathrm{NiSO}_{4} \cdot 6 \mathrm{H}_{2} \mathrm{O}$ & 0.56 & - & 0.56 & 0.56 \\
\hline $\mathrm{K}_{2} \mathrm{Cr}_{2} \mathrm{O}_{7}$ & 0.20 & 0.20 & - & 0.20 \\
\hline $\mathrm{C}_{4} \mathrm{H}_{6} \mathrm{O}_{4} \mathrm{~Pb} \cdot 3 \mathrm{H}_{2} \mathrm{O}$ & - & - & 0.23 & 0.23 \\
\hline
\end{tabular}

Table 1. Contents of feeding medium used during microorganism isolation from soil samples.

\subsection{Characteristics and experimental setup of the bioreactor}

The HRTB is a stainless steel tube with $2.0 \mathrm{~m}$ length and $0.25 \mathrm{~m}$ diameter. O-ring-shaped partition walls (inner diameter $0.19 \mathrm{~m}$ ) divide its interior in a $0.02 \mathrm{~m}$ long section. The liquid volume of the bioreactor was $15 \mathrm{~L}$. In order to enable rotation of the entire reactor, the HRTB is horizontally placed on appropriate bearings. The aeration was performed via the central tube fixed in the bioreactor's axis. Improvement of the aeration was obtained by submerging the aeration tube on five positions along the HRTB. For all experimental works, the airflow rate was $152 \mathrm{~L} \mathrm{~h}^{-1}$. In Figure 1 the sampling systems for broth and biofilm are shown, being places at 
$0.40 \mathrm{~m}$ intervals. On the cover of the sampling place, a flat plate $(0.02 \times 0.02 \mathrm{~m})$ is fixed as device for biofilm thickness measurement.
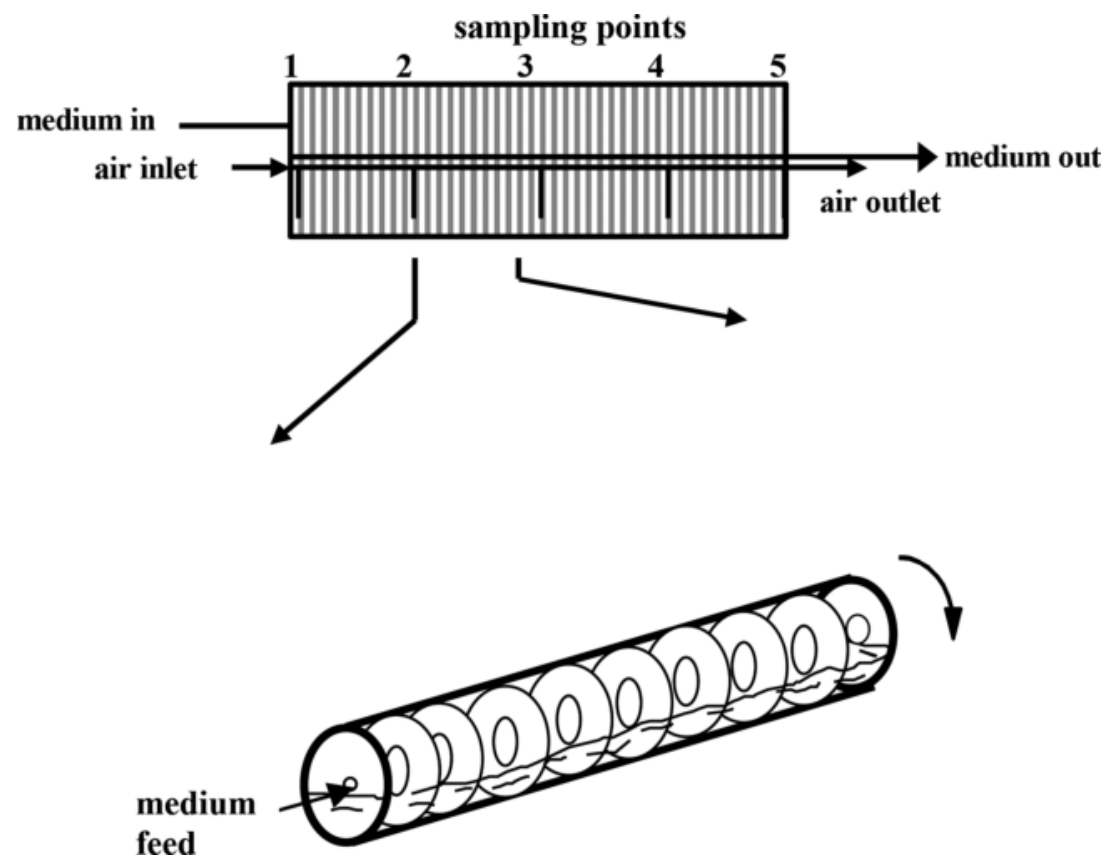

Figure 1. Schematic diagram of HRTB and the inner structure of HRTB with O-ring-shaped partition walls.

Batch cultivation in a stirred tank bioreactor is used to obtain the suspended bacterial biomass $(7.5 \mathrm{~L})$ needed for inoculating the HRTB. The feeding process was started after $24 \mathrm{~h}$ at a rate of $1 \mathrm{~L} \mathrm{~h}^{-1}$ and a rotation speed of the HRTB of $10 \mathrm{~min}^{-1}$. A stable biofilm in the bioreactor is available after 15 days, which is considered as ready to start the experiments with different parameter variations, such as medium inflow rate $\left(0.5,1.0\right.$, and $\left.2.0 \mathrm{~L} \mathrm{~h}^{-1}\right)$ and bioreactor rotation speed $\left(5,15\right.$, and $\left.30 \mathrm{~min}^{-1}\right)$. The dynamics of the bioprocess in HRTB was monitored by withdrawing the samples from five positions along the bioreactor length after five residence times since the new set of process parameters was established. The bioreactor was operated under a constant influent glucose concentration $10 \mathrm{~g} \mathrm{~L}^{-1}$ and metal ion concentration $\mathrm{Co}^{2+}=0.125 \mathrm{~g} \mathrm{~L}^{-1}, \mathrm{Mn}^{2+}=0.125 \mathrm{~g} \mathrm{~L}^{-1}$, and $\mathrm{Cr}^{6+}=0.125 \mathrm{~g} \mathrm{~L}^{-1}$.

Since it was known in previous studies that bioreactor rotation speed higher than $30 \mathrm{~min}^{-1}$ leads to intensive biofilm detachment [23, 25], no higher speed are tested in the current investigation. Experiments with varying bioreactor rotation speed are carried out prior to changes of medium inflow rate, since the latter have exhibited higher effects on the bioprocess dynamics and the biofilm stability [23, 24, 26, 27]. 


\subsection{Analytical methods}

Biomass concentration in suspension was determined by centrifuging the culture medium of $35 \mathrm{~mL}$ for $20 \mathrm{~min}$ at $4500 \mathrm{rpm}$ (3629 g), washing twice with demineralized water and then drying at $105^{\circ} \mathrm{C} / 48 \mathrm{~h}$. Supernatants were used for determination of $\mathrm{Co}^{2+}, \mathrm{Mn}^{2+}$, and $\mathrm{Cr}^{6+}(\mathrm{UV}-$ Vis spectrophotometrical method by Fries and Getrost) [28]. All determinations were done in triplicates.

Inductively coupled plasma-mass spectrometry (ICP-MS) was used to quantify the metals in biofilm and suspended biomass after acidic digestion. The spectrometer used had a GemCone nebulizer, a cyclone spray chamber, and a standard one-piece extended torch with a quartz injector tube. Each metal was quantified by measurements in triplicates at three different wavelengths. The biofilm samples were mineralized using a closed microwave digestion system. Each sample was digested with a mixture of $5 \mathrm{~mL}$ nitric acid, $1 \mathrm{~mL}$ hydrogen peroxide, and $1 \mathrm{~mL}$ double-distilled water. The digestion was performed in five steps $-3 \mathrm{~min}$ at $250 \mathrm{~W}$, $1 \mathrm{~min}$ without power, $4.5 \mathrm{~min}$ at $250 \mathrm{~W}, 6 \mathrm{~min}$ at $650 \mathrm{~W}$, and $5 \mathrm{~min}$ at $400 \mathrm{~W}$-followed by a ventilation time of $25 \mathrm{~min}$.

The biofilm thickness was measured applying a modified Venkataraman and Ramanujam method [29]: graphite powder was used instead of chalk powder. The projector was replaced by a microscope with micrometric scale. In order to determine the mass of the biofilm, samples were collected from the inner surface of HRTB, suspended in demineralized water, and twice washed after centrifugation. Finally the biofilm samples were dried for $48 \mathrm{~h}$ at $105^{\circ} \mathrm{C}$.

Suspended biomass sorption capacity $\left(q_{x, L}\right)$ was calculated as follows:

$$
q_{x, L}=\frac{m_{M}}{m_{x, L}}
$$

where $m_{M}$ mass of metal ion (mg) and $m_{x \cdot L}$ is the dry weight of suspended biomass (g).

\subsection{Mathematical model development}

\subsubsection{Diffusion process}

The diffusivity of metal ion in water was estimated using the Wilke-Chang equation [30]:

$$
D_{a q}=7.4 \cdot 10^{-8} \frac{\left(\xi_{a q} M_{a q}\right)^{1 / 2} T}{V_{M}^{0.6} \eta_{a q}}
$$

where $D_{a q}$ is the diffusion coefficient of metal ion in water $\left(\mathrm{m}^{2} \mathrm{~s}^{-1}\right), \xi$ is the metal ion connecting factor, $V_{M}$ is the metal ion molar volume $\left(\mathrm{m}^{3} \mathrm{~mol}^{-1}\right), \eta$ is the water dynamic viscosity $\left(\mathrm{kg} \mathrm{m}^{-1} \mathrm{~s}^{-1}\right), T$ is the temperature $(\mathrm{K})$, and $M_{a q}$ is the water molecular mass $\left(\mathrm{kg} \mathrm{mol}^{-1}\right)$.

Metal ion relative diffusivity $\left(f_{D}\right)$ was computed from Horn-Morgenroth equation [31]: 


$$
f_{D}=1-\frac{0.43 c_{x, f}{ }^{0.92}}{11.19+0.27 c_{x, f} 0.99}
$$

where $c_{x, f}$ is the biofilm density $\left(\mathrm{kg} \mathrm{m}^{-3}\right)$.

Effective diffusion coefficient of metal ion in biofilm was calculated using this correlation [32]:

$$
D_{e f, M}=f_{D} D_{a q}
$$

where $D_{e f, M}$ is the effective diffusion coefficient of metal ion in biofilm $\left(\mathrm{m}^{2} \mathrm{~s}^{-1}\right)$.

Mass transport of all dissolved metal ions in biofilm follows Fick's second law of molecular diffusion:

$$
D_{e f, M} \frac{\partial^{2} c_{M, f}}{\partial z^{2}}=\frac{\partial c_{M, f}}{\partial t}
$$

where $c_{M, f}$ is the concentration of metal ion in biofilm phase $\left(\mathrm{kg} \mathrm{m}^{-3}\right), t$ is time (s), and $z$ is biofilm depth (m).

\subsubsection{One-dimensional diffusion-bioadsorption model}

In the dynamic equilibrium conditions, metal ion concentration in the biofilm is represented conceptually as functions of biofilm depth $z$ as shown in Figure 2C. Concentrations of metal ion $\left(c_{M, f}\right)$ in biofilm phase are given by the second-order polynomial correlation:

$$
c_{M, f}(z)=a_{0}+a_{1} z+a_{2} z^{2}
$$

where $a_{0}, a_{1}$, and $a_{2}$ are the second-order polynomial correlation coefficient and $z$ is biofilm depth coordinate $(\mathrm{m})$.

Metal ion concentrations in the bulk liquid phase $\left(c_{M, L}\right)$ represent as constant values for each ideal mixing segment (Figure 2B, C).

The biofilm zone is surrounded by the stagnant liquid layer of thickness $L_{g}$ (Figure 2C). The mass transfer coefficient $\left(k_{m}\right)$ in the stagnant liquid layer was estimated by the correlation $[18,19]$ :

$$
k_{m}=0.664\left(D_{t b} / L_{k}\right) R e_{N}{ }^{1 / 2} S c^{1 / 3}
$$

where $L_{K}$ is the wetted perimeter of bioreactor $(0.254 \mathrm{~m}), D_{t b}=D_{a q}$ is the diffusion coefficients of metal ions in water $\left(\mathrm{m}^{2} \mathrm{~h}^{-1}\right), S c$ is Schmidt number, and $R e_{N}$ is Reynolds rotation number. Schmidt number $(S c)$ was calculated from [33]

$$
S c=v / D_{t b}
$$

where $v$ is kinematic viscosity $\left(\mathrm{m}^{2} \mathrm{~s}^{-1}\right)$.

Reynolds rotation number $\left(R e_{N}\right)$ of HRTB was calculated by following equation [18]: 


$$
\operatorname{Re}_{N}=\frac{D_{U P} \pi n L_{K} \rho}{2 \eta}+\frac{D_{T} \Pi n L_{K} \rho}{2 \eta}
$$

where $D_{\text {UP }}$ is the inner diameter of partition wall in HRTB $(\mathrm{m}), L_{K}$ is wetted perimeter of bioreactor $(0.254 \mathrm{~m}), \Pi$ is the Ludolph's number (3.14159), $D_{\mathrm{T}}$ is the bioreactor diameter $(\mathrm{m}), n$ is the bioreactor rotation speed $\left(\mathrm{s}^{-1}\right), \rho$ is the broth density $\left(\mathrm{kg} \mathrm{m}^{-3}\right)$, and $\eta$ is the dynamic viscosity of broth $\left(\mathrm{kg} \mathrm{m}^{-1} \mathrm{~s}^{-1}\right)$.

Regarding to "spiral flow" mixing model [18, 19], based on the physical model which divided the bioreactor into ideally mixed compartments (Figure 2A), mass balances of the heavy metal ion for the first ideal mixing segment across the bulk liquid (Figure 2A, B) were

$$
V_{L}^{1,1} \frac{d c_{M, L}^{1,1}}{d t}=F_{u} c_{M, L}^{0}+F_{c r} c_{M, L}^{1, N i}+F_{p} c_{M, L}^{2,1}-\left(F_{u}+F_{p}\right) c_{M, L}^{1,1}-F_{c r} c_{M, L}^{1,1}-V_{L}^{1,1} r_{M, L}^{1,1}
$$

where $c_{M, L}^{1,1}$ is liquid section metal ion concentrations in the first segment $(N i=1)$ of the first kaskade $(\mathrm{Nl}=1)\left(\mathrm{kg} \mathrm{m}^{-3}\right), c_{M, L}^{0}$ is inflow metal ion concentration $\left(\mathrm{kg} \mathrm{m}^{-3}\right), F_{u}$ is inflow $\left(\mathrm{m}^{3} \mathrm{~h}^{-1}\right), F_{p}$ is back flow $\left(\mathrm{m}^{3} \mathrm{~h}^{-1}\right), F_{c r}$ is circulation flow $\left(\mathrm{m}^{3} \mathrm{~h}^{-1}\right), r_{M, L}^{1,1}$ is liquid section reaction rate in the first segment $(N i=1)$ of first kaskade $(N l=1)\left(\mathrm{kg} \mathrm{m}^{-3} \mathrm{~h}^{-1}\right), V_{L}^{1,1}$ is liquid section volume in the first segment $(N i=1)$ of the first kaskade $(N l=1)\left(\mathrm{m}^{3}\right)$, and $c_{M, L}^{1, N i}$ is liquid section metal ion concentrations in the $\mathrm{Ni}$-segment of the first kaskade $\left(\mathrm{kg} \mathrm{m}^{-3}\right)$.

First ideal mixing segments of all cascades were represented in the model without biofilm zone (Figure 2B). All other ideal mixing segments include biofilm zone (Figure 2C). Therefore, mass

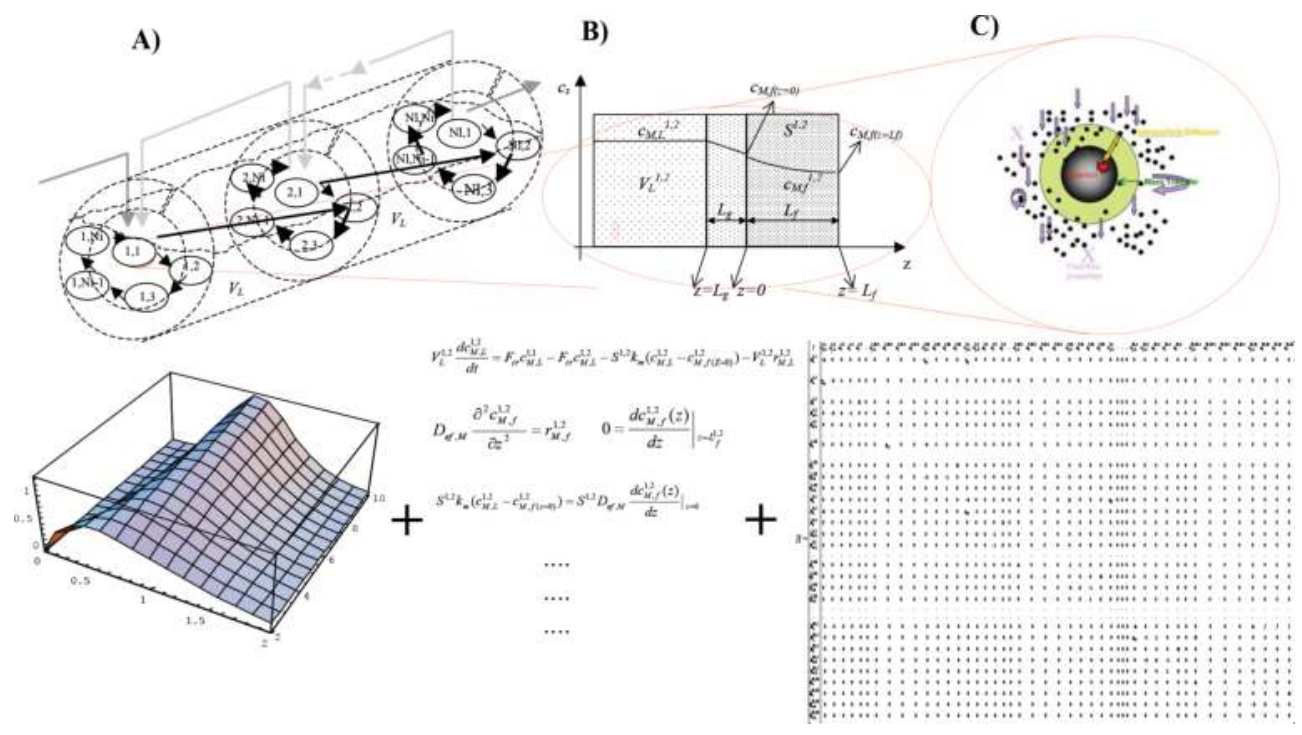

Figure 2. Conceptual representation of metal biosorption in HRTB: (A) "spiral flow" mixing, (B) metal ion diffusion, and (C) biosorption reaction. 
balances of the heavy metal ion were computed across the bulk liquid for the second ideal mixing segment (Figure 2A, C) as follows:

$$
V_{L}^{1,2} \frac{d c_{M, L}^{1,2}}{d t}=F_{c r} c_{M, L}^{1,1}-F_{c r} c_{M, L}^{1,2}-S^{1,2} k_{m}\left(c_{M, L}^{1,2}-c_{M, f(\mathrm{Z}=0)}^{1,2}\right)-V_{L}^{1,2} r_{M, L}^{1,2}
$$

where $c_{M, L}^{1,2}$ is liquid section metal ion concentrations in the second segment $(N i=2)$ of the first kaskade $(\mathrm{Nl}=1)\left(\mathrm{kg} \mathrm{m}^{-3}\right), c_{M, f(\mathrm{Z}=0)}^{1,2}$ is metal ion concentration in the second segment $(\mathrm{Ni}=2)$ of the first kaskade $(\mathrm{Nl}=1)$ on the biofilm surface $\left(\mathrm{kg} \mathrm{m}^{-3}\right), V_{L}^{1,2}$ is liquid section volume in the second segment $(N i=2)$ of the first kaskade $(N l=1)\left(\mathrm{m}^{3}\right), S^{1,2}$ is mass transfer surface in second ideal mixing segment $(\mathrm{Ni}=2)$ of the first kaskade $(\mathrm{Nl}=1)\left(\mathrm{m}^{2}\right)$, and $r_{M, L}^{1,2}$ is liquid section reaction rate in the second segment $(\mathrm{Ni}=2)$ of the first kaskade $(\mathrm{Nl}=1)\left(\mathrm{kg} \mathrm{m}^{-3} \mathrm{~h}^{-1}\right)$.

Liquid section volume in the ideal mixing segment $\left(V_{L}^{N l, N i}\right)$ was computed from the bioreactor liquid volume using the following equation:

$$
V_{L}^{N l, N i}=\frac{V_{L}}{N l \cdot N i}
$$

where $V_{L}^{N l, N i}$ is liquid section volume in the ideal mixing segment $\left(\mathrm{m}^{3}\right), V_{L}$ is liquid volume in the HRTB $\left(\mathrm{m}^{3}\right), \mathrm{Nl}$ is the number of kaskades, and $\mathrm{Ni}$ is the number of ideal mixing segments.

Mass transfer surface in the ideal mixing segment $\left(S^{N l, N i}\right)$ was computed from the inside bioreactor surface using the following equation:

$$
S^{N l, N i}=\frac{S}{N l \cdot N i}
$$

where $S^{N l, N i}$ is mass transfer surface in the ideal mixing segment $\left(\mathrm{m}^{2}\right)$ and $S$ is inside bioreactor surface $\left(\mathrm{m}^{2}\right)$.

Mass transport of all dissolved metal ions in biofilm is derived from Eq. (5) and equal to reaction rate $\left(r_{M, f}^{1,2}\right)$ :

$$
D_{e f, M} \frac{\partial^{2} c_{M, f}^{1,2}}{\partial z^{2}}=r_{M, f}^{1,2}
$$

The inner boundary conditions (at $z=0$ ) at biofilm-liquid interface are given as

$$
S^{1,2} k_{m}\left(c_{M, L}^{1,2}-c_{M, f(z=0)}^{1,2}\right)=\left.S^{1,2} D_{e f, M} \frac{d c_{M, f}^{1,2}(z)}{d z}\right|_{z=0}
$$

The outer boundary conditions (at $z=L_{f}^{1,2}$ ) at biofilm-bioreactor interface are given as

$$
0=\left.\frac{d c_{M, f}^{1,2}(z)}{d z}\right|_{z=L_{f}^{1,2}}
$$

As mentioned before, concentrations of the metal ion in the biofilm are represented with 
second-order polynomial correlation [Eq. (6)]. Assuming dynamic equilibrium conditions at time $(t)$ model were derived from mass balances equation [Eqs. (11), (14), (15)] and secondorder polynomial correlation for metal ion concentration [Eq. (6)], taken across biofilm zone vertical to the biofilm surface [Eqs. (17)-(20) below]:

Bulk liquid section:

$$
0=F_{c r} c_{M, L}^{1,1}-F_{c r} c_{M, L}^{1,2}-S^{1,2} k_{m}\left(c_{M, L}^{1,2}-a_{0}^{1,2}\right)-V_{L}^{1,2} r_{M, L}^{1,2}
$$

Biofilm zone:

$$
D_{e f, M} 2 a_{2}^{1,2}=r_{M, f}^{1,2}
$$

The inner boundary conditions (at $z=0$ ):

$$
-\frac{k_{m}}{D_{e f, M}}\left(c_{M, L}^{1,2}-a_{0}^{1,2}\right)=a_{1}^{1,2}
$$

The outer boundary conditions (at $z=L_{f}^{1,2}$ ):

$$
a_{1}^{1,2}=-2 a_{2}^{1,2} L_{f}^{1,2}
$$

where $a_{0}^{1,2}, a_{1}^{1,2}$, and $a_{2}^{1,2}$ are the second-order polynomial correlation coefficient in the second segment $(N i=2)$ of the first kaskade $(N l=1) ; L_{f}^{1,2}$ biofilm thickness in the second segment $(\mathrm{Ni}=2)$ of the first kaskade $(\mathrm{Nl}=1)(\mathrm{m}) ; V_{L}^{1,2}$ is liquid section volume in the second segment $(\mathrm{Ni}=2)$ of the first kaskade $(\mathrm{Nl}=1)\left(\mathrm{m}^{3}\right)$; and $r_{M, L}{ }^{1,2}$ is liquid section reaction rate in the second segment $(N i=2)$ of the first kaskade $(N l=1)\left(\mathrm{kg} \mathrm{m}^{-3} \mathrm{~h}^{-1}\right)$.

Adjusting mass balances and reaction rates for all ideal mixing segments according to Figure 2, system of the differential equations was developed for heavy metal ion concentration changes along HRTB.

\subsubsection{Bioadsorption kinetic model}

Mass balance equations were coupled to the reaction rate terms in the liquid section $\left(r_{M, L}\right)$ and in the biofilm zone $\left(r_{M, f}\right)$ based on the Freundlich adsorption isotherm. Instead kinetic terms heavy metal removal was changed with bioadsorption model [34] [Eqs. (21), (22)]:

$$
\begin{aligned}
& q_{x, L}=K_{F}\left(c_{M, L}\right)^{1 / h} \\
& q_{x, f}=K_{F}\left(c_{M, f}\right)^{1 / h}
\end{aligned}
$$

were $q_{x, L}$ is suspended biomass adsorption capacity $\left(\mathrm{mg} \mathrm{g}^{-1}\right), q_{x, f}$ is biofilm adsorption capacity $\left(\mathrm{mg} \mathrm{g}^{-1}\right)$, and $K_{F}$ and $h$ are Freundlich isotherm constant.

Bioadsorption model for biofilm zone was derived from Freundlich equation [Eq. (22)] and second-order polynomial correlation for metal ion biofilm concentration [Eq. (6)]: 


$$
q_{x, f}=K_{F}\left[a_{0}+a_{1} z_{i}+a_{2}\left(z_{i}\right)^{2}\right]^{1 / h}
$$

where $z_{i}$ is collocation point across biofilm zone parallel to the substratum surface.

Assuming the collocation point $z_{i}=L_{f} / b$ where $b \in \mathrm{N}(+)$ bioadsorption model are defined as follows:

$$
q_{x, f}=K_{F}\left[a_{0}+a_{1} \frac{L_{f}}{b}+a_{2}\left(\frac{L_{f}}{b}\right)^{2}\right]^{1 / h}
$$

The kinetic model assumes that reaction rate is the function of biomass concentration in the liquid section $\left(c_{x, L}\right)$ and in the biofilm zone $\left(c_{x, f}\right)$ [Eqs. (25), (26) below]:

$$
\begin{aligned}
& r_{M, L}=\frac{c_{x, L} q_{x, L}}{\tau} \\
& r_{M, f}=\frac{c_{x, f} q_{x, f}}{\tau}
\end{aligned}
$$

where $r_{M, f}$ is biofilm section reaction rate $\left(\mathrm{kg} \mathrm{m}^{-3} \mathrm{~h}^{-1}\right), r_{M, L}$ is liquid section reaction rate $\left(\mathrm{kg} \mathrm{m}^{-3} \mathrm{~h}^{-1}\right)$, and $\tau$ is retention time (h).

\subsubsection{Numerical methods}

The model equations were solved by personal computer using the "Wolfram Mathematica" program routine "NDSolve, FindRoot, FindMinimum, Fit," and orthogonal collocation methods [35-37] were applied for the inner biofilm concentration profiles representing.

\subsubsection{Initial parameter values}

The model was initially simulated using kinetic parameters $\left(K_{F}\right.$ and $\left.h\right)$ from previous studies [38] and mixing parameters $\left(\mathrm{Nl}, \mathrm{Ni}, \mathrm{F}_{\mathrm{cr}}\right.$ and $\mathrm{F}_{p}$ ) computed in this study (Table 1). Transport parameters include the mass transfer coefficient rate of metal ions $\left(k_{m}\right)$, and the effective diffusion coefficient of metal ion in biofilm $\left(D_{e f, M}\right)$ was estimated by Eqs. (7) and (2)-(4).

\subsubsection{Parameter optimization}

The empirical equations developed from HRTB mixing modeling were used as a fitness function during mixing parameter optimization $\left(N l, N i, F_{c r}\right.$ and $\left.F_{p}\right)$. Kinetic parameters $\left(K_{F}\right.$ and $\left.h\right)$ were optimized computing variance between observed variables and simulated variables as

$$
E_{n}=\frac{1}{n_{u}} \sum_{i=1}^{i=n_{u}} \frac{\left(c_{n, \exp }^{i}-c_{n, \operatorname{sim}}^{i}\right)^{2}}{c_{n, \exp }^{i}}
$$

where $c_{n, \exp }^{i}$ is observed variables $\left(\mathrm{kg} \mathrm{m}^{-3}\right), c_{n, \operatorname{sim}}^{i}$ is simulated variables $\left(\mathrm{kg} \mathrm{m}^{-3}\right)$, and $n_{u}$ is number of observations. 
To determine dependence of parameter change on variance between observed variables and simulated variables $\left(E_{n}\right)$, calculation were performed by polynomial regression with the "Wolfram Mathematica" routine "Fit." After this plug, optimization was preformed calculating global minimum variance between observed variables and simulated variables using routine "FindMinimum."

\section{Results and discussion}

\subsection{Biofilm formation studies in HRTB}

In this work the effect of process parameters ( $n$ and $F$ ) on the mixed microbial culture biofilm formation in HRTB was studied as a continuation of comprehensive research of mixing [18-20] and conduction of model bioprocesses in HRTB [23-27]. This investigation started with mixed microbial culture isolation from surface sediments highly contaminated with heavy metals [39-41].

Isolated mixed microbial culture was developed in HRTB as described in Section 2.2, whereby the culture first grew in suspension and then a biofilm was gradually established on the Oshaped rings and inner surface of bioreactor. Figure 3 represents $\mathrm{O}$-shaped rings before and after biofilm formation.

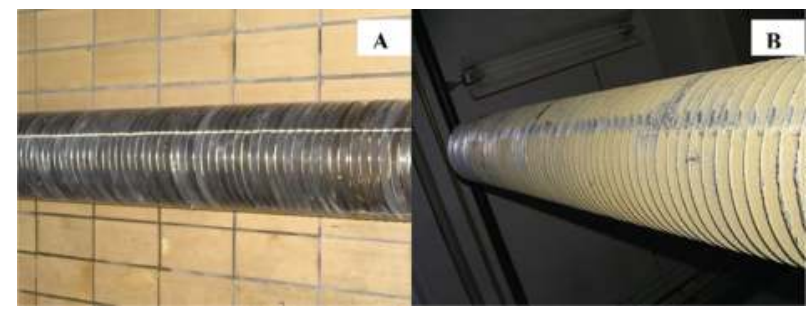

Figure 3. O-shaped rings before (A) and after (B) biofilm formation in HRTB.

The biofilm obtained was used for the investigation of suspended biomass adsorption abilities and biofilm properties (thickness, density) by different combinations of process parameters. Changes of process parameters $(n$ and $F)$ during this investigation are presented in Figure 4.

A significant disturbance was observed at $\mathrm{F}=2.0 \mathrm{~L} \mathrm{~h}^{-1}$ and $\mathrm{n}=30 \mathrm{~min}^{-1}$ when biofilm detachment took place. Influence of biofilm detachment on suspended biomass concentration changes will be discussed in the next section.

\subsection{Suspended biomass concentration and biosorption capacity in HRTB}

In the present study, biomass grew as suspended single cells, suspended cell clusters, and biofilm attached to the bioreactor inner surface. Table 2 shows the results of suspended biomass concentration in dependency of parameter variation: inflow rate $\left(\mathrm{F}=0.5-2.0 \mathrm{~L} \mathrm{~h}^{-1}\right)$ and bioreactor rotation speed $\left(\mathrm{n}=5-30 \mathrm{~min}^{-1}\right)$. The suspended biomass concentrations $\left(c_{x . L}\right)$ range from 0.95 to $1.07 \mathrm{~g} \mathrm{~L}^{-1}$ at inflow rate $0.5 \mathrm{~L} \mathrm{~h}^{-1}$. The increase of the inflow rate to 1.0 and 


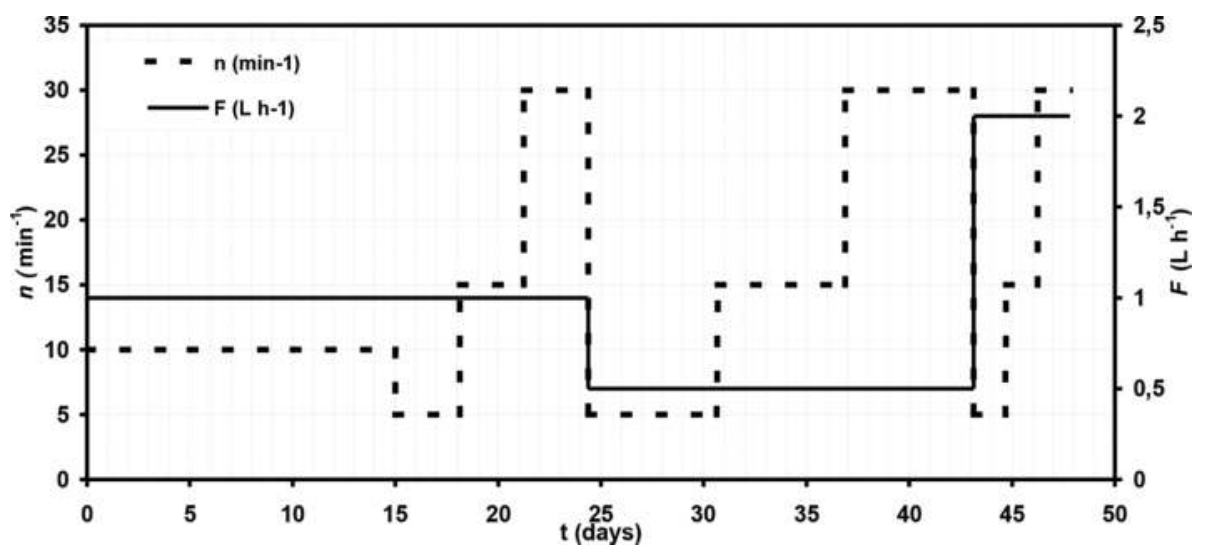

Figure 4. Dynamics of process parameter changes [bioreactor rotation speed (n) and medium inflow rate (F)] during investigation in the HRTB.

$2.0 \mathrm{~L} \mathrm{~h}^{-1}$ was related to the increase of suspended biomass concentrations $\left(1.59-5.11 \mathrm{~g} \mathrm{~L}^{-1}\right)$ as a consequence of biofilm detachment and erosion. Highest suspended biomass concentration was $5.11 \mathrm{~g} \mathrm{~L}^{-1}$ registrated as a consequence of more intensive biofilm detachment (release of larger biofilm parts) due to high inflow rate $\left(\mathrm{F}=2.0 \mathrm{~L} \mathrm{~h}^{-1}\right)$ and bioreactor rotation speed $\left(\mathrm{n}=30 \mathrm{~min}^{-1}\right)$. In this situation, considerable increase of metal ion concentrations was observed as a consequence of biomass washout from HRTB. Biofilm detachment (erosion and sloughing) is a complex process affected by hydrodynamic conditions together with morphological and physiological characteristics of the biofilm $[8,42]$. Suspended biomass changes were also observed at inflow rates $\left(1.0-2.0 \mathrm{~L} \mathrm{~h}^{-1}\right)$ for all bioreactor rotation speed $\left(5-30 \mathrm{~min}^{-1}\right)$ as a consequence of biofilm erosion (continuous release of smaller biofilm parts) [43].

The suspended biomass biosorption capacity $\left(q_{x . L}\right)$ during heavy metal removal is presented in Table 3. The inflow rate had a more pronounced effect on the biosorption capacity than the bioreactor rotation speed. Nevertheless, highest bioreactor rotation speed $\left(30 \mathrm{~min}^{-1}\right)$ decreased thickness of stagnant liquid layer at the biomass surface and provided facilitate condition for metal ion adsorption. The increase of the inflow rate to 1.0 and $2.0 \mathrm{~L} \mathrm{~h}^{-1}$ was related to the increase of biomass biosorption capacity. Microbial biomass concentration and content have a significant effect on the biosorption capacity. Therefore, higher biomass biosorption capacity was observed for inflow rates 1.0 and $2.0 \mathrm{~L} \mathrm{~h}^{-1}$ where higher microbial biomass concentration and biofilm erosion were observed (Table 2). Biofilm structure and extracellular polysaccharide content increase possibility for metal ion accumulation. Molecule of extracellular polysaccharide has high molecular mass and enhanced capability for metal ion bonding [13, 42, 44-47]. Due to the biofilm detachment observed for $\mathrm{F}=2.0 \mathrm{~L} \mathrm{~h}^{-1}$ and $\mathrm{n}=30 \mathrm{~min}^{-1}$ and release of microbial biomass with high amount of biofilm, biosorption capacity reached highest value of $83.27 \mathrm{mg} \mathrm{g}^{-1}$, respectively.

Biological and hydrodynamic factors (content of extracellular polymers and cell physiological and morphological state of same microbial species) have influence on the suspended biomass 


\begin{tabular}{llll}
\hline$F\left(\mathrm{~L} \mathrm{~h}^{-1}\right)$ & $n\left(\mathrm{~min}^{-1}\right)$ & & \\
\cline { 2 - 4 } & $\mathbf{5}$ & $\mathbf{1 5}$ & $\mathbf{3 0}$ \\
\hline 0.5 & 1.08 & 0.95 & 1.02 \\
1.0 & 1.59 & 1.74 & 2.48 \\
2.0 & 2.67 & 2.89 & 5.11 \\
\hline
\end{tabular}

Table 2. The suspended biomass concentration $\left(c_{x . L}\right)$ changes at different combinations of bioreactor process parameters $(n$ and $F$ ) during heavy metal removal process.

\begin{tabular}{|c|c|c|c|}
\hline \multirow[t]{2}{*}{$F\left(\mathrm{~L} \mathrm{~h}^{-1}\right)$} & \multicolumn{3}{|c|}{$n\left(\min ^{-1}\right)$} \\
\hline & 5 & 15 & 30 \\
\hline 0.5 & 28.45 & 18.51 & 33.75 \\
\hline 1.0 & 33.59 & 48.79 & 71.62 \\
\hline 2.0 & 58.73 & 58.01 & 83.27 \\
\hline
\end{tabular}

Table 3. Metal ion sorption capacity $\left(q_{x . L}\right)$ changes at different combinations of bioreactor process parameters $(n$ and $F)$ during heavy metal removal process.

biosorption capacity. Situation is more complex in mixed culture where different microbiological content and cell distribution also influence biosorption capacity. In addition, hydrodynamic conditions have also influence on all previous denominate biological factors [8]. Therefore, on the basis of these results, it is clear that biological hydrodynamic conditions in HRTB have a significant effect on the suspended biomass concentration and biosorption capacity (Tables 2 and 3 ).

\subsection{Biofilm volumetric density and thickness along HRTB}

Since the sampling point at $75 \%$ of reactor length was also used for introducing the temperature sensor, the biofilm thickness could be measured only at four sampling sites. The differences in biofilm thickness given by changing medium inflow rate $\left(\mathrm{F}=0.5-2.0 \mathrm{~L} \mathrm{~h}^{-1}\right)$ and bioreactor rotation speed $\left(\mathrm{n}=5-30 \mathrm{~min}^{-1}\right)$ are presented in Table 4 . The biofilm thickness was in the range of $0.23-1.43 \mathrm{~mm}$ that is thinner than the literature data for mixed culture biofilm but thicker than monomicrobial culture biofilm thickness measured in previous research [25].

The biofilm thickness in the bioreactor $L_{f}$ was mainly stabile for inflow rates 0.5 and $1 \mathrm{~L} \mathrm{~h}^{-1}$, and only smaller biofilm parts were observed in the liquid phase as a consequence of the biofilm erosion process. This tendency was maintained until the inflow rate became $2 \mathrm{~L} \mathrm{~h}^{-1}$. Afterward, hydrodynamic conditions and high metal load inhibited biofilm growth and decreased biofilm thickness. The resultant accumulation of metal ions had an impact on the biofilm, its strength, and its density. In these conditions intensive detachment of the biofilm was observed. The increase of the inflow rate produces thinner biofilm with higher density. Therefore, the outer biofilm layers are more sensitive to the shear stress and abrasion than the 


\begin{tabular}{|c|c|c|c|c|}
\hline \multirow[t]{2}{*}{$F\left(\mathrm{~L} \mathrm{~h}^{-1}\right)$} & \multirow[t]{2}{*}{$n\left(\min ^{-1}\right)$} & \multicolumn{3}{|l|}{$L_{f}(\mathrm{~mm})$} \\
\hline & & ( $\left.0 \% L_{\text {HRTB }}\right)$ & $\left(50 \% L_{\text {HRTB }}\right)$ & $\left(100 \% L_{\text {HRTB }}\right)$ \\
\hline \multirow[t]{3}{*}{0.5} & 5 & 0.75 & 1.08 & 0.89 \\
\hline & 15 & 0.89 & 0.73 & 0.81 \\
\hline & 30 & 0.93 & 1.29 & 0.85 \\
\hline \multirow[t]{3}{*}{1.0} & 5 & 0.85 & 1.34 & 0.95 \\
\hline & 15 & 0.92 & 1.43 & 0.84 \\
\hline & 30 & 0.86 & 1.21 & 0.91 \\
\hline \multirow[t]{3}{*}{2.0} & 5 & 0.23 & 0.37 & 0.28 \\
\hline & 15 & 0.35 & 0.28 & 0.25 \\
\hline & 30 & 0.38 & 0.37 & 0.35 \\
\hline
\end{tabular}

Table 4. Biofilm thickness changes $\left(L_{f}\right)$ along HRTB at different medium inflow rates $\left(F=0.5-2.0 \mathrm{~L} \mathrm{~h}^{-1}\right)$ and bioreactor rotation speed $\left(n=5-30 \mathrm{~min}^{-1}\right)$ during heavy metal removal bioprocess.

inner biofilm layers. Moreover, outer biofilm layers can be released even at relatively small shear stress. After this, the detachment rate is considerably reduced [12, 47]. Thinner biofilms are less sensitive to process condition changes, which has positive influence on the process stability [44]. The impact of the biofilm detachment on the bioprocess was less pronounced from bioreactor inflow rate (Table 4).

Biofilm volumetric density $\left(c_{x . f}\right)$ for $F=2.0 \mathrm{~L} \mathrm{~h}^{-1}$ and $n=30 \mathrm{~min}^{-1}$ was measured at the inlet and the outlet of the HRTB. The HRTB is characterized by concentration gradient along bioreactor, so consequently higher volumetric biofilm density was observed at the inlet of HRTB $\left(59.7 \pm 5.2 \mathrm{~g} \mathrm{~L}^{-1}\right)$ than at the outlet of HRTB $\left(39.3 \pm 4.4 \mathrm{~g} \mathrm{~L}^{-1}\right)$. Similar results were observed during previous investigation of metal ion removal in HRTB [38].

The reason for this finding might be that the substrate concentrations for microorganism growth decrease with bioreactor length. Higher volumetric biofilm density was related to increase the biofilm sorption capacity. Both properties are influenced by structure and content of biofilm. Differences in extracellular polysaccharide content affect the gradient of the linkage strength between cell clusters inside the biofilm. While cells on the surface of the biofilm grow relatively fast and do not accumulate, cells inside the biofilm have lower growth rates and produce more extracellular polysaccharides [13, 42, 44-46]. The extracellular polysaccharides affect the microbial sorption capacity by their content and molecular size. The outer biofilm layer exhibits higher porosity, resulting in easier metal ion access to deeper layers. Additionally, high-volumetric-density biofilms have higher sorption capacity than the low-density biofilms that are characterized by the low content of extracellular polysaccharides [48].

\subsection{Biofilm application in removal of $\mathrm{Co}(\mathrm{II}), \mathrm{Cr}(\mathrm{IV})$, and $\mathrm{Mn}$ (II) from wastewater}

After biofilm formation and characterization, investigation of biofilm sorption abilities in removal of $\mathrm{Co}(\mathrm{II}), \mathrm{Cr}(\mathrm{IV})$, and $\mathrm{Mn}(\mathrm{II})$ was done at different combinations of medium inflow rates and constant HRTB rotation speed. Results are presented as equilibrium metal ion 
concentration along HRTB in the liquid phase. Equilibrium metal ion concentration was reached after five residence time changes.

The metal ion concentrations along HRTB at different medium inflow rates $\left(\mathrm{F}=0.5-2.0 \mathrm{~L} \mathrm{~h}^{-1}\right)$ and constant bioreactor rotation speed $\left(\mathrm{n}=15 \mathrm{~min}^{-1}\right)$ are presented in Figure 5 (Co(II) concentration Figure 5A, Cr(VI) concentration Figure 5B, Mn(II) concentration Figure 5C). Points represent measured values, while simulated values are represented with curves. Metal ion concentration changes along HRTB were simulated using one-dimensional diffusionbiosorption model and optimized parameter values [38]. The inflow of all metal ion (Co(II), $\mathrm{Cr}(\mathrm{VI})$, and $\mathrm{Mn}(\mathrm{II}))$ concentration was $0.125 \mathrm{~g} \mathrm{~L}^{-1}$, respectively. Lower metal ion concentrations were detected at a first measuring point in the bioreactor (located at the place of medium inflow, $0 \% \mathrm{~L}_{\text {HRTB }}$ ) because of medium dilution at this location in the HRTB.

Generally, increase in the inflow rate $(F)$ caused increase of metal ion concentration along bioreactor. Higher inflow rate increased metal ion load in HRTB and concentration of metal ions in liquid phase. Metal ion concentration in biomass was in a dynamic equilibrium with metal ion concentration in the liquid phase. Biomass (solid phase) in bioreactor becomes saturated with metal ions and reaches maximum removal capacity. Consequence of biomass saturation is the decrease of metal ion concentration in the liquid phase (Figure 5).

As shown in previously performed hydrodynamic experiments in HRTB, medium flow in the bioreactor can be determined by plug-flow conditions [21]. These are attributed to the formation of temperature and/or concentration gradients along the reactor length [16]. Decrease in the metal ion concentration gradient along the bioreactor length in the second part of the HRTB (measurements points on $50 \%$ and $100 \% \mathrm{~L}_{\text {HRTB }}$ ) confirmed assumption of the plug-flow condition in HRTB (Figure 5). The highest metal ion concentration measured near the place of medium inflow (measurement points $0 \%$ and $25 \% \mathrm{~L}_{\mathrm{HRTB}}$ ) inhibited biomass
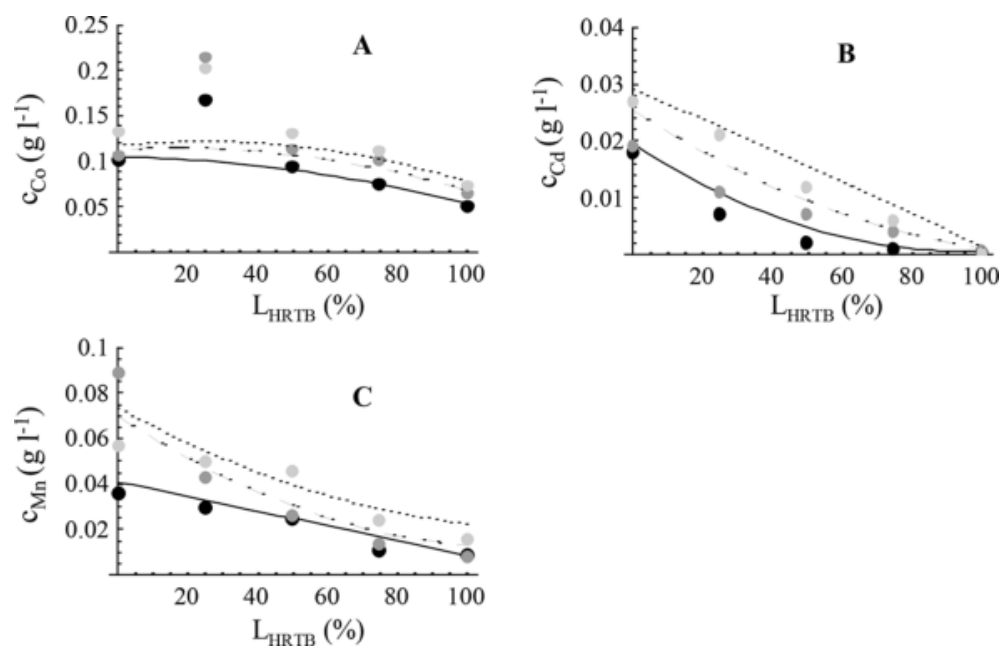

Figure 5. Concentration of $\mathrm{Co}(\mathrm{A}), \mathrm{Cr}(\mathrm{B})$, and $\mathrm{Mn}(\mathrm{C})$ ion along the HRTB at different medium inflow rates $F=0.5 \mathrm{~L} \mathrm{~h}^{-1}$ (black dots, solid line), $F=1.0 \mathrm{~L} \mathrm{~h}^{-1}$ (dark gray dots, dashed line), $F=2.0 \mathrm{~L} \mathrm{~h}^{-1}$ (light gray dots, dot line), and constant bioreactor rotation speed $\left(n=15 \mathrm{~min}^{-1}\right)$. 
activity and produced a considerable deviations from plug-flow conditions. As was previously mentioned (in the Section 3.2), the biofilm biosorption is a complex process that is affected by hydrodynamic conditions as well as morphological and physiological characteristics of the biofilm $[49,50]$.

\section{Conclusion}

Microbial strains were isolated from heavy metal-contaminated surface sediments and selected due to their ability to grow in the presence of metal ions. The results obtained in this study proved technical feasibility of isolated strains to form biofilm in HRTB and to remove metal ions from contaminated water with concentrations up to $500 \mathrm{mg} \mathrm{L}^{-1}$. The microbial removal ability was higher at lowest medium inflow rates of 0.5 . When the inflow rate was in the range of 1.0-2.0 $\mathrm{L} \mathrm{h}^{-1}$, microbial removal ability was reduced.

Generally, the medium inflow rate had more pronounced effect on the bioprocess dynamics than bioreactor rotation speed. The biofilm biosorption capacity was reduced with decreased biofilm density. Similar trend shows suspended biomass biosorption capacity and suspended biomass concentration. The obtained results prove that HRTB can be successfully used for conducting the removal of heavy metals with isolated microbial strains.

\section{Acknowledgements}

This chapter is supported by Croatian Science Foundation project UIP-2014-09-1534 and SPECH-LRM-9158 for which the authors are grateful. Any findings, conclusions, and remarks are of authors only and do not necessarily reflect the standings of Croatian Science Foundation.

\section{Author details}

Tonči Rezić ${ }^{1 *}$, Iva Rezić ${ }^{2}$, Michaela Zeiner ${ }^{3}$ and Božidar Šantek ${ }^{1}$

*Address all correspondence to: trezic@pbf.hr

1 Department of Biochemical Engineering, Faculty of Food Technology and Biotechnology, University of Zagreb, Zagreb, Croatia

2 Department of Applied Chemistry, Faculty of Textile Technology, University of Zagreb, Zagreb, Croatia

3 Department of Chemistry, University of Natural Resources and Life Sciences, BOKU Vienna, Wien, Austria 


\section{References}

[1] Deng L, Su Y, Su H, Wang X, Zhu X. Biosorption of copper (II) and lead (II) from aqueous solutions by nonliving green algae Cladophora fasciculares: equilibrium, kinetics and environmental effects. Adsorption. 2006;12:267-277.

[2] Kadirvelu K, Palanivel M, Kalpana R, Rajeswari S. Activated carbon from agricultural product, for the treatment of dyeing industry wastewater. Bioresour Technol. 2000;74:263-265.

[3] Pandey G, Jain RK. Bacterial chemotaxis toward environmental pollutants: role in bioremediation. Appl Environ Microbiol. 2002;68:5789-5795.

[4] Valko M, Morris H, Cronin MTD. Metals, toxicity and oxidative stress. Curr Med Chem. 2005;12:1161-1208.

[5] Gardea-Torresday JL, Tang L, Salvador JM. Copper adsorption by esterified and unesterified fractions of sphagnum peat moss and its humic substances. J Hazard Matter. 1996;48:191-206.

[6] Wang J, Chen C. Biosorbents for heavy metals removal and their future. Biotechnol Adv. 2009;27:195-226.

[7] Patterson JW. Industrial wastes reduction. Environ Sci Technol. 1989;23:1032-1038.

[8] Gavrilescu M. Removal of heavy metals from the environment by biosorption. Eng Life Sci. 2004;3:219-232.

[9] Gadd GM. Biosorption: critical review of scientific rationale, environmental importance and significance for pollution treatment. J Chem Technol Biotechnol. 2008;84:13-28.

[10] Singh R, Paul D, Jain RK. Biofilms: implications in bioremediation. Trends Microbiol. 2006;14:387-397.

[11] Kratochvil D, Volesky B. Advances in biosorption of heavy metals. Trends Biotechnol. 1998;16:291-300.

[12] Gavril M, Macoveanu M. Attached-growth process engineering in wastewater treatment. Bioproc Eng. 2000;23:95-106.

[13] Nicolella C, Loosdrecht MCM, Heijnen JJ. Wastewater treatment with particulate biofilm reactor. J Biotechnol. 2000;80:1-33.

[14] Gupta AB, Gupta SK. Simultaneous carbon and nitrogen removal from high strength domestic wastewater in an aerobic RBC biofilm. Wat Res. 2001;35:1714-1722.

[15] Moser A. Imperfectly mixed bioreactor systems. In: Moo-Young M (ed) Comprehensive biotechnology, vol. 2, Pergamon Press, Oxford; 1985. pp. 77-98.

[16] Moser A. Bioprocess technology kinetics and reactors. Springer, Wien New York; 1988.

[17] Kargi F, Eker S. Comparison of the performance of rotating perforated tubes and rotating biodisc biofilm reactors for wastewater treatment. Proc Biochem. 2001;37:1201-1206. 
[18] Šantek B, Horvat P, Novak S, Mayr B, Moser A, Marić V. Mathematical modeling of mixing in horizontal rotating tubular bioreactor: "simple flow" model. Bioproc Eng. 1996;14:195-204.

[19] Šantek B, Horvat P, Novak S, Mayr B, Moser A, Marić V. Mathematical modeling of mixing in horizontal rotating tubular bioreactor: "simple flow" model. Bioproc Eng. 1996;14:223-229.

[20] Šantek B, Horvat P, Novak S, Moser A, Marić V. Studies on mixing in a horizontal rotating tubular bioreactor. Part I: optimisation of adjustable parameters for "spiral flow" model. Bioproc Eng. 1998;18:467-473.

[21] Šantek B, Horvat P, Novak S, Moser A, Marić V. Studies on mixing in a horizontal rotating tubular bioreactor. Part II: prediction systems for adjustable parameters of "spiral flow" model. Bioproc Eng. 1998;19:19-28.

[22] Šantek B, Horvat P, Novak S, Moser A, Marić V. Studies on mixing in a horizontal rotating tubular bioreactor. Part III: influence of liquid level and distance between the partition walls on prediction systems for adjustable model parameters. Bioproc Eng. 1998;19:91102.

[23] Ivančić M, Šantek B, Novak S, Marić V. Fermentative bioconversion in a horizontal rotating tubular bioreactor. Proc Biochem. 2004;39:995-1000.

[24] Slavica A, Šantek B, Novak S, Marić V. Microbial acetate oxidation in horizontal rotating tubular bioreactor. J Biosci. 2004;29:169-177.

[25] Rezić T, Šantek B, Novak S, Marić V. Heterotrophic cultivation of Paracoccus denitrificans in a horizontal rotating tubular bioreactor. World J Microbiol Biotechnol. 2007;23:987-996.

[26] Rezić T, Šantek B, Novak S, Marić V. Comparison between the heterotrophic cultivation of Paracoccus denitrificans in continuous stirred tank reactor and horizontal rotating tubular bioreactor. Proc Biochem. 2006;41:2024-2028.

[27] Ivančić M, Šantek B, Novak S, Horvat P, Marić V. Bioprocess kinetics in a horizontal rotating tubular bioreactor. Bioprocess Biosyst Eng. 2004;26:169-175.

[28] Fries J, Getrost H. Organic reagents for trace analysis. Merck Laboratory Press, Darmstadt; 1977.

[29] Venkataraman R, Ramanujam TK. A study on microbiology of biological film layer in rotating biological contactors. Bioproc Eng. 1998;18:181-186.

[30] Wilke CR, Chang P. Correlation of diffusion coefficients in dilute solutions. AIChE J. 1955;1:264-270.

[31] Horn H, Morgenroth E. Transport of oxygen, sodium chloride and sodium nitrate in biofilms. Chem Eng Sci. 2006;61:1347-1356.

[32] Stewart PS. Diffusion in biofilms. J Bacteriol. 2003;185:1485-1491. 
[33] Garrido JM, van Benthem W, van Loosdrecht MCM, Heijnen JJ. Influence of dissolved oxygen concentration on nitrite accumulation in a biofilm airlift suspension reactor. Biotechnol Bioeng. 1997;53:168-178.

[34] Freundlich H. Über die Adsorption in Lösungen. [On the adsorption in solutions; article in German] Z Phys Chem. 1907;57:385-470.

[35] Arora S, Dhaliwal SS, Kukreja VK. Application of orthogonal collocation on finite elements for solving non-linear boundary value problems. Appl Math Comput. 2006;18:516-523.

[36] Villadsen J, Stewart WE. Solution of boundary value problems by orthogonal collocation. Chem Eng Sci. 1967;22:1483-1501.

[37] Leitão A, Rodrigues A. Modeling of biodegradation/adsorption combined processes in fixed-bed biofilm reactors: effects of the intraparticle convective flow. Chem Ing Sci. 1996;51:4595-4604.

[38] Rezic T, Zeiner M, Santek B, Novak S. Mathematical modeling of Fe(II), Cu(II), Ni(II) and $\mathrm{Zn}$ (II) removal in a horizontal rotating tubular bioreactor. Bioprocess Biosyst Eng. 2011;34:1067-1080.

[39] Mikac N, Foucher D, Kwokal Ž, Barišiæ D. Mercury and radionuclides in sediments of the Kaštela bay (Croatia)- evaluation of the sediment pollution history. Croat Chem Acta. 2006;79:85-93.

[40] Bogner D. Surface sediments and influence of the physico-chemical characteristics of the sediment on the distribution of heavy metals in the Kaštela bay, in Croatian [MSc thesis]. University of Zagreb, Zagreb; 1996.

[41] Stegnar P, Vukadin I, Smodiš B, Vakselj A, Prosenc A. Trace elements in sediments and organisms from Kaštela bay. J. Etud. Pollut. CIESM. 1980;5:596-600.

[42] Peyton BM. Effects of shear stress and substrate loading rate on Pseudomonas aeruginosa biofilm thickness and density. Wat Res. 1996;30:29-36.

[43] Brading MG, Jass J, Lappin-Scott HM. Dynamics of bacterial biofilm formation. In: Lappin-Scott HM, Costerton JW (eds.) Microbia biofilms, Cambridge University Press, Cambridge; 1995. pp. 46-63.

[44] Liu Y, Tay J. The essential role of hydrodynamic shear force in the formation of biofilm and granular sludge. Wat Res. 2002;36:1653-1665.

[45] Stoodley P, Sauer K, Davies DG, Costerton JW. Biofilms as complex differentiated communities. Annu Rev Microbiol. 2002;56:187-209.

[46] Stoodley P, Hall-Stoodley L, Lappin-Scott HM. Detachment, surface migration and other dynamic behavior in bacterial biofilms revealed by digital time-lapse imaging. Methods Enzymol. 2000;337:306-319. 
[47] Characklis WG. Biofilm processes. In: Characklis WG, Marshall KC (eds.) Biofilms, Wiley, New York; 1990. pp. 93-130.

[48] Cloirec P, Andres Y, Faur-Brasquet C, Gerente C. Engineered biofilms for metal ion removal. Rev Environ Sci Biotechnol. 2003;2:177-192.

[49] Quintelas C, Fonseca B, Silva B, Figueiredo H, Tavares T. Treatment of chromium(VI) solutions in a pilot-scale bioreactor through a biofilm of Arthrobacter viscosus supported on GAC. Bioresour Technol. 2009;100:220-226.

[50] Van Hullebusch ED, Zandvoort MH, Lens PNL. Metal immobilization by biofilms: mechanisms and analytical tools. Rev Environ Sci Bio Technol. 2003;2:9-33. 